\title{
PECVD Yöntemi ile Polimerik Hidrojel İnce Filmlerin Üretimi
}

\author{
Mehmet GÜRSOY* \\ Konya Teknik Üniversitesi, Kimya Mühendisliği Bölümü, Konya
}

\begin{abstract}
$\ddot{\mathbf{O} z}$
Bu çalışma ile hidrojel özellikteki PHPMA (poli(hidroksipropil metakrilat)) ince filmleri gaz fazı bir yöntem olan plazma destekli kimyasal buhar biriktirme (PECVD) yöntemi ile üretilmiştir. Substrat sıcaklığının, reaktör basıncının ve plazma gücünün, PHPMA ince filmlerinin kaplama hızları üzerine etkileri incelenmiştir. PECVD parametrelerinin, PHPMA ince filmlerinin morfolojileri, kimyasal yapıları ve sslanabilirlik özellikleri üzerine etkileri açığa çıkarılmıştır. Ayrıca, bu çalışma kapsamında PHPMA ince filmlerinin, kaplama mekanizması ve kinetiği de incelenmiştir. En yüksek kaplama hızı $(120,2 \mathrm{~nm} / \mathrm{dk}) 20^{\circ} \mathrm{C}$ substrat sıcaklığında, $250 \mathrm{mtorr}$ reaktör basıncında ve $20 \mathrm{~W}$ plazma gücünde elde edilmiştir. PHPMA kaplamasının aktivasyon enerjisi $-22,16 \mathrm{~kJ} / \mathrm{mol}$ olarak bulunmuştur.
\end{abstract}

Anahtar kelimeler: CVD, PHPMA, Hidrojel, İnce film.

\section{Synthesis of Polymeric Hydrogel Thin Films by PECVD Method}

\begin{abstract}
In this study, PHPMA (poly (hydroxypropyl methacrylate)) thin films, which have hydrogel properties, were synthesized by gas phase plasma enhanced chemical vapor deposition (PECVD) method. The effects of substrate temperature, reactor pressure and plasma power on the deposition rates of PHPMA thin films were investigated. The effect of PECVD parameters on the morphology, chemical structure and wettability properties of PHPMA thin films were revealed. Furthermore, the deposition mechanisms and kinetics of PHPMA thin films were also investigated in this study. The highest deposition rate $(120.2 \mathrm{~nm} / \mathrm{min})$ was obtained at the substrate temperature of $20^{\circ} \mathrm{C}$, reactor pressure of $250 \mathrm{mtorr}$ and plasma power of $20 \mathrm{~W}$. The activation energy of PHPMA deposition was found to be $-22.16 \mathrm{~kJ} / \mathrm{mol}$.
\end{abstract}

Keywords: CVD, PHPMA, Hydrogel, Thin film.

\section{Giriş}

Sahip oldukları önemli özelliklerden dolayı polimerik hidrojellere karşı olan ilgi her geçen gün artarak devam etmektedir. $\mathrm{Bu}$ özellikler arasında, biyouyumlu olmaları, reaktif fonksiyonel grupları, kimyasalları veya hücreleri hareketsiz hale getirebilme yeteneği yer almaktadır [1-7]. Yapılarında bulunan $-\mathrm{OH},-\mathrm{NH}_{2},-\mathrm{SO}_{3} \mathrm{H}$ ve $-\mathrm{COOH}$ benzeri hidrofilik özellikteki fonksiyonel gruplar sayesinde büyük miktarlarda suyu absorbe edebilme ve tutabilme kabiliyetleri vardır. Ayrıca, $\mathrm{pH}$, sıcaklık, manyetik, elektriksel alan, 1şık gibi çevre koşullarına göre bir takım kimyasal ve fiziksel özelliklerinin değişebilmesi de polimerik hidrojellere çeşitli kullanım alanları sunmaktadır [8-12].

Polimerik hidrojel ince filmlerin, dayanıklı olması, tekrarlanabilirliği yüksek bir şekilde üretilebilmesi ve endüstrinin ihtiyaçlarını karşılayabilecek miktarlarda üretimi arzulanmaktadır. Arzu edilen özellikteki polimerik hidrojel ince filmlerin üretimi için, üretim yöntemi dikkatlice seçilmelidir. Bugüne kadar polimerik hidrojelleri üretmek için birçok yöntem kullanılmıştır. Polimerik hidrojelleri üretmek için kullanılan yöntemler çözelti bazlı yöntemler (1slak prosesler) ve gaz fazı yöntemler (kuru prosesler) olmak üzere iki grup altında toplanabilir. Atom transferi radikal polimerizasyonu (ATRP),

"Sorumlu yazar: mgursoy@ktun.edu.tr

Geliş Tarihi: 15.02.2019, Kabul Tarihi: 01.07.2019. 
daldırma kaplama, sol-jel teknikleri, çözelti bazlı polimer hidrojel üretim yöntemlerini oluşturmaktadır [13]. Kolay uygulanabilmesi ve özel ekipmanlara ihtiyaç duymamasından dolayı, sslak yöntemler yaygın bir şekilde polimerik hidrojel film üretiminde kullanılmaktadır. Ancak, bu yöntemlerin uygulanması esnasında kullanılan çözeltiler, bazı problemlere neden olmaktadır. Örneğin, ilaç salınımı uygulamalarında nano ve/veya mikro boyuttaki malzemelerin enkapsülasyonunun yapılmas1 gerekebilmektedir. Çözelti bazlı yöntemlerde kullanılan sıvıların yüzey gerilimleri sonucu parçacıkların birbirine yapışmasına ve bunun neticesinde parçacıkların topaklaşmasına sebep olabilmektedir $[14,15]$. Gözenekli yapıların enkapsülasyonunda kullanılan sıvılar, malzeme yapısındaki gözenekleri kapatabilir. Öte yandan gaz fazı ince film üretim yöntemlerinden olan kimyasal buhar biriktirme (CVD) yönteminde herhangi bir çözelti kullanılmaması birçok avantajı bünyesinde bulundurmasını sağlamaktadır. Örneğin, çözelti bazlı yöntemlerle kaplanması mümkün olamayan 1slanmaya karşı hassas yüzeylere zarar vermeden kaplamalar yapmak mümkün olabilmektedir. Geometrik olarak girintili çıkıntılı yüzeylerin, yüzey yapılarını bozmadan açıkorur kaplamalara olanak vermektedir [16, 17]. Ayrıca, kaplamalar esnasında herhangi bir çözelti kullanılmaması, çözelti bazlı kaplama yöntemlerinde olduğu gibi ortamdaki çözeltinin giderimi için bir çaba ve maliyet gerektirmemektedir. Genellikle CVD yöntemi ile ince film üretiminde, başlatıcılı kimyasal buhar biriktirme (iCVD) ve plazma destekli kimyasal buhar biriktirme (PECVD) yöntemleri tercih edilmektedir. Her ne kadar iCVD yöntemi ile elde edilen kaplamalardaki fonksiyonel grupların korunumu daya yüksek olsa da özellikle homopolimer olarak üretilen filmlerin çözeltilere dayanımı ve kaplanan yüzeye tutunumları beklentinin altında kalabilmektedir. PECVD yöntemiyle yapılan kaplamalarda ise, yoğun enerjik ortam filmlerin çapraz bağlanmasına sebep olarak dayanımı yüksek filmlerin eldesini mümkün kılmaktadır [18]. Yoğun plazma ortamı aynı zamanda substrat yüzeylerinde nano ve mikro boyutta pürüzlülük oluşturabilmektedir [19]. Bu durum ince filmlerin, yüzeylere tutunumunu artırabilmektedir. Ayrıca, büyük ölçekli kaplamalar göz önüne alındığında iCVD kaplamaları sadece filament tellerin altında yer alan kısıtlı alanda gerçekleşebilirken, PECVD kaplamaları reaktör içerisindeki tüm alanda gerçekleşebilmesi mümkündür. Dolayısıyla, iCVD yöntemi ile kıyaslandığında, PECVD sistemi ile çok daha geniş yüzey alanlarının kaplanması mümkündür. Bu çalışma kapsamında sahip olduğu tüm bu avantajlarından dolayı, ince film üretiminde PECVD yöntemi tercih edilmiştir.

$\mathrm{Bu}$ çalışma ile, hidrojel özellikteki PHPMA (poli(hidroksipropil metakrilat)) polimeri, tek adımda gerçekleştirilen PECVD yöntemi kullanılarak üretilmiştir. Farklı substrat sıcaklığı, reaktör basınc1 ve plazma güçlerinde üretilen PHPMA ince filmleri, silikon tabaka ve bu çalışma kapsamında üretilen PMMA (Poli(metil metakrilat)) fiber yüzeylerine kaplanmıştır. Yapılan çalışmalarla PECVD parametrelerinin, PHPMA ince film kaplama mekanizması ve sslanabilirlik özellikleri üzerine etkileri incelenmiştir.

\section{Materyal ve Metot}

\subsection{Materyal}

Monomer olarak kullanılan \%97 saflıktaki hidroksipropil metakrilat (HPMA) Sigma-Aldrich'den satın alınıp; herhangi bir saflaştırma işlemine ya da modifikasyona tabii tutulmadan doğrudan kullanılmışı̧r. HPMA monomerinin, kimyasal yapısı şematik olarak Şekil 1'de gösterilmiştir. Sigma-Aldrich'den satın alınan 150000 ortalama molekül ağırlığına sahip PMMA ve \%99,8 saflıktaki dimetilformamit (DMF) kullanılarak elektro eğirme fiberleri hazırlanmıştır. Yapılan kaplama işlemlerinde, substrat olarak silikon tabaka (100, p-tipi) ve bu çalısma kapsamında üretilen elektroeğirme PMMA fiberleri kullanılmıştır. 


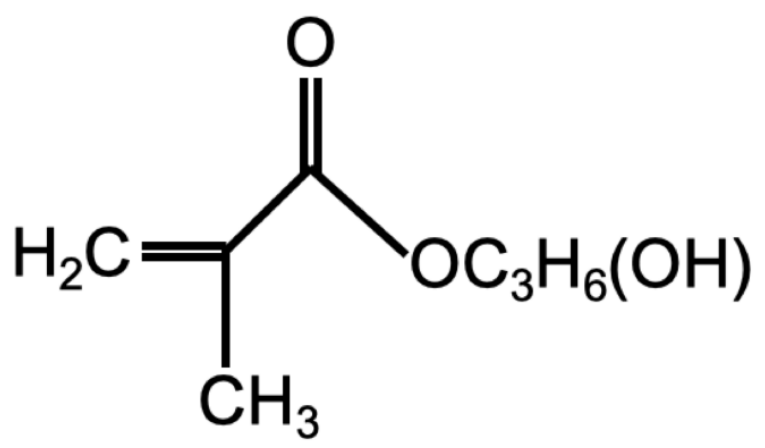

Şekil 1. HPMA monomerinin kimyasal yapısı

\subsection{PECVD ince film kaplamaları}

PHPMA ince filmlerinin üretiminde RF (Radyo Frekans1) tipi bir PECVD reaktörü kullanılmıştır (Şekil 2). Substratlar, altında çevirmeli su banyosuna bağlı 1sı değiştiricisi bulunan, reaktör zeminine yerleştirilmiştir. Su banyosunun sıcaklığı değiştirilerek, substrat sıcaklığ 1 değiştirilmiştir. Substrat sıcaklığı olarak verilen değerler, ayarlanan su banyosunun değerleridir. HPMA monomerinin içerisine konduğu çelik kap ve monomer kabını reaktöre bağlayan hat üzeri 1sıtıcı bantlarla sarılmıştır. Isıtıcı bantlar, PID tipi sıcaklık kontrol edici bir sistem kullanılarak 1sitılmıştır. Monomer, $65^{\circ} \mathrm{C}$ 'ye 1 sitılıp; bu değerde sabit tutulmuştur. Monomer buharının, reaktöre ilerlediği hat duvarlarına çarpıp yoğuşmaması için ise hat daha yüksek bir sıcaklığa $\left(75^{\circ} \mathrm{C}\right)$ 1sıtılıp; bu sıcaklıkta deney boyunca sabit tutulmuştur. Monomer ile reaktör arasındaki hat üzerinde bulunan iğne vana ile monomerin akış hızı ayarlanmıştır. Yapılan tüm deneylerde monomer $0,54 \mathrm{sccm}$ akış hızı ile vakum altındaki PECVD reaktörüne beslenmiştir. Polimerleşme için gerekli olan aktivasyon enerjisi bir adet 13,56 MHz RF plazma kaynağ aracılığı ile sağlanmıştır. Reaktörün kuvars kapağın hemen üzerine konumlandırılmış bakır anten aracıllğ alan plazma eşleştiricisi ile plazma güç kaynağında ayarlanan plazma gücünün düzgün bir şekilde antenlere iletilmesini sağlamıştır. Deneyler esnasında reaktör içerisindeki basınç, kapasitans tipi bir manometre aracılığ 1 ile okunmuştur; çalışılmak istenen basınç değerleri, PID kontrollü bir basınç kontrol sistemi ve ona bağlı olan kelebek vana aracılığı ile ayarlanmıştır.

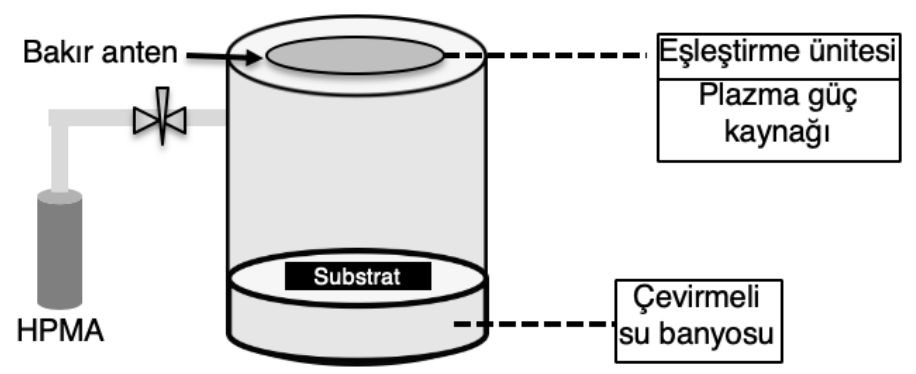

Şekil 2. PECVD sistemi şematik çizim

Deneysel parametre olarak, reaktör basıncı, substrat sıcaklığı ve plazma gücü çalışılmıştır. Kaplama hızları, kaplanan filmlerin temas açıları, kimyasal ve morfolojik yapıları ise bağımlı parametreler olarak çalışılmıştır. Çalışılan PECVD deneysel parametreleri, Tablo 1'de verilmiştir.

Tablo 1. Çalışılan PECVD deneysel parametreleri

\begin{tabular}{cc}
\hline Parametreler & Değerler \\
\hline Monomer akış hızı $(\mathrm{sccm})$ & 0,54 \\
Substrat sicaklı̆̆ $\left({ }^{\circ} \mathrm{C}\right)$ & $20,30,40,50$ \\
Plazma gücü (W) & $1,20,40,60$ \\
Reaktör basıncı (mtorr) & $75,150,250,350,450$ \\
\hline
\end{tabular}




\subsection{Elektroeğirme PMMA fiberlerinin üretimi}

Elektroeğirme PMMA fiberlerini üretmek için gerekli olan çözelti, 2 g PMMA, 30 mL DMF içerisinde 1sıtmalı manyetik karıştırıcı üzerinde $80^{\circ} \mathrm{C}$ sıcaklıkta, $200 \mathrm{rpm}$ karıştırma hızında 2 saat boyunca karıştırılarak elde edilmiştir. Hazırlanan çözelti oda sıcaklığına kadar soğutulduktan sonra, şırınga içerisine konulmuştur. Elektroeğirme sistemi olarak, NE-100 Inovenso cihazı kullanılmıştır. Şırınga ucu ile toplayıcı üzerinde bulunan alüminyum folyo arasındaki mesafe $15 \mathrm{~cm}$ olacak şekilde ayarlanmıştır. Polimer çözeltisinin akış hızı saatte $0,3 \mathrm{~mL}$ olarak ayarlanmıştır. Şırınga ucuna $20 \mathrm{kV}$ güç uygulanmıştır.

\subsection{Karakterizasyon işlemleri}

Elde edilen filmlerin kimyasal yapıları, FTIR analizleri ile aydınlatılmıştır. Bruker Vertex 70 FTIR spektrum cihazı ile yapılan çalışmalar $4 \mathrm{~cm}^{-1}$ çözünürlükte, atenüe tam yansıtıcı (ATR) aparatı ile gerçekleştirilmiştir. ATR aparatı sayesinde numunelerin FTIR analizleri, herhangi bir ön işleme gerek duyulmadan, doğrudan yapılabilmiştir.

Elektroeğirme PMMA fiberleri kaplandıktan sonra, SEM analizi ile kaplanmadan önceki ve sonraki fiber yüzeylerinin morfolojileri incelenmiştir. SEM analizleri, Zeiss marka LS-10 model cihazı kullanılarak, ikincil elektron modunda, $20 \mathrm{kV}$ güçte gerçekleştirilmiştir. Numuneler, üzerinde karbon disk bulunan alüminyum iskelete sahip numune tutucu üzerine yerleştirilip, yaklaşık $5 \mathrm{~nm}$ kalınlığında bir altın tabaka ile püskürtme cihazı (Model 108, Cressington Scientific Instruments Ltd) kullanılarak kaplanmıştır.

Temas açıları, OCA 50 Model (Data Physics Instruments $\mathrm{GmbH}$ ) genyometrik tipi temas açısı cihazı kullanılarak ölçülmüsşür. Bu amaçla incelenecek yüzeylere $2 \mu \mathrm{L}$ hacminde su damlatılmıştır.

PECVD sisteminin reaktör kapağında yer alan kuvars cam üzerinde sisteme entegre halde bulunan lazer interferometre sistemi vasitasıyla, kaplamalar esnasında anlık kalınlık kontrolü yapılmıştır. Deneyler tamamlandıktan sonra, silikon tabaka üzerindeki film kalınlıkları, Avantes marka reklektometre cihazı ile tekrar ölçülüp; kontrol edilmiştir.

\section{Bulgular ve Tartışma}

\subsection{PHPMA filmlerinin kaplama kinetiği}

Çalışmada PHPMA filmlerinin kaplama hızları, silikon tabaka üzerindeki film kalınlıklarından yola çıkılarak hesaplanmıştır. İnterferometre ile ölçülen kaplama kalınlıkları, reflektometre cihazı ile de ölçülmüş̧ür. Her iki kaplama değeri sonuçları da benzer çıkmıştır. Reaktör basınçlarının, kaplama hızlarına etkisi, sabit sıcaklıkta farklı plazma güçlerinde araştırılmıştır. Bu kapsamda, substrat sıcaklığı $20^{\circ} \mathrm{C}$ 'de sabit tutulup; 1, 20, 40 ve $60 \mathrm{~W}$ plazma güçlerinde; 75, 150, 250, 350 ve 450 mtorr basınçlarında kaplamalar yapılmıştır. Bu çalışma kapsamında gerçekleştirilen deneylerde, mevcut PECVD parametrelerinde 75 mtorr'dan daha düşük basınçlarda kararlı HPMA plazması elde edilememiştir. Bundan dolayı en düşük reaktör basıncı olarak 75 mtorr'da çalışılmıştır. Yine mevut deneysel şartlarda, 450 mtorr reaktör basıncının üzerindeki değerlerde, reaktör içerisinde monomerin yer yer yoğuştuğu gözlemlendiğinden 450 mtorr'dan daha yüksek basınç değerlerinde kaplamlar yapılmamıştır.

Reaktör basıncının ve plazma gücünün, PHPMA ince film kaplama hızları üzerine etkisi Şekil 3 'teki grafikte gösterilmiştir. Tüm reaktör basınçlarda, $1 \mathrm{~W}$ plazma gücü uygulandığında en düşük kaplama hızları elde edilmiştir. Plazma gücü $20 \mathrm{~W}$ 'a ulaştığında ise en yüksek kaplama hızları elde edilmiştir. Plazma gücü, $40 \mathrm{~W}$ 'a çıkarıldığında ise kaplama hızları, $20 \mathrm{~W}$ plazma gücünde elde edilen kaplama hızlarına göre düşmüştür. Aynı koşullar altında, plazma gücü $60 \mathrm{~W}$ 'a çıkarıldığında ise kaplama hızlarındaki düşüş artmıştır. Çalışmada gözlemlenen plazma güçleri ile kaplama hızları arasındaki ilişki, beklenen bir durumdur. Çünkü, plazma polimerizasyonlarında, genellikle belli bir plazma gücüne kadar, uygulanan plazma gücü arttıkça, polimerlerin kaplama hızlarının da artması beklenmektedir. Ancak, belli bir plazma gücünden sonra, yoğun plazma ortamının aşındırıcı etkisi; kaplama etkisinin önüne geçebilmektedir. Bu noktadan sonra, plazma gücünün artması ile kaplama hızlarında bir düşüş ile karşılaşılabilmektedir [20]. 


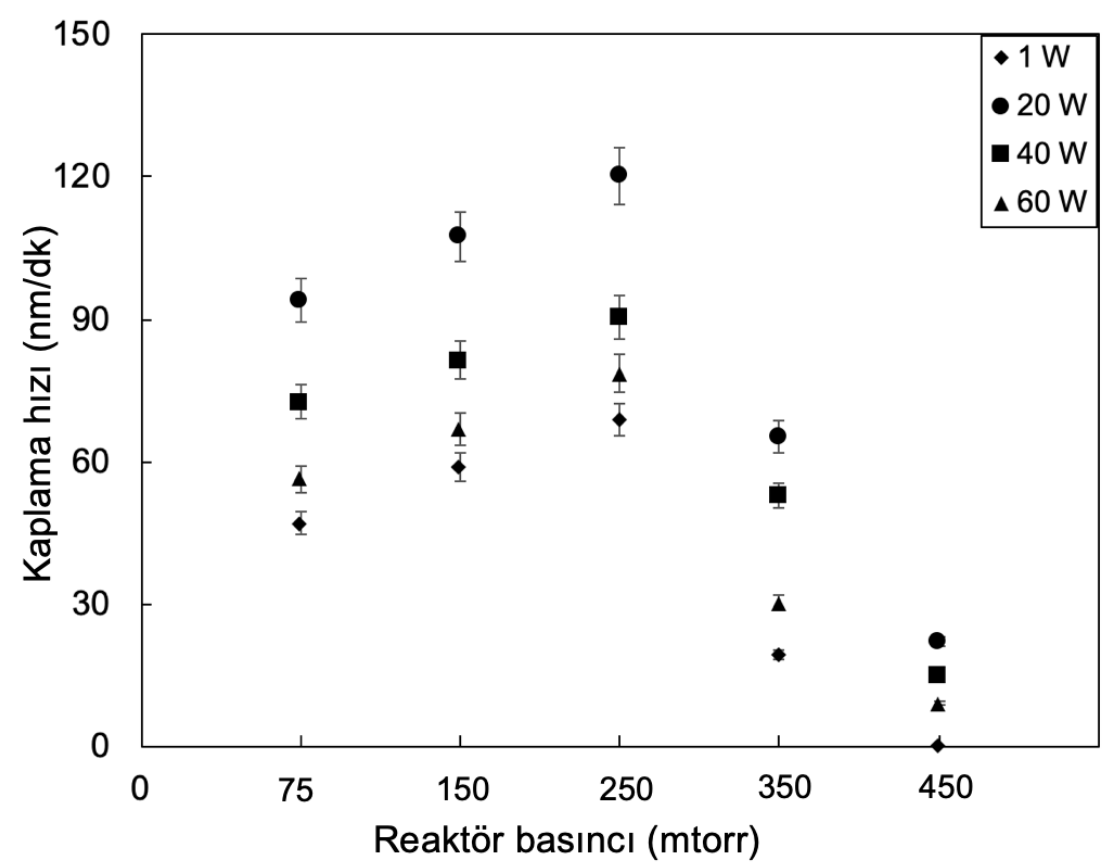

Şekil 3. Farklı reaktör basınçlarındaki plazma güçlerinin üretilen filmlerin kaplama hızlarına etkisi

Şekil 3'te görüldüğ̈̈ üzere, tüm plazma güçlerinde, reaktör basıncı 75 mtorr'dan 250 mtorr'a yükseltildiğinde kaplama hızlarının arttığı gözlemlenmiştir. Artan basınç ile reaktör içesinde bulunan gaz moleküllerinin konsantrasyonu artmaktadır. Bunun sonucunda, gaz moleküllerinin alıkonma süresinin artması ve gaz molekülleri arasındaki ortalama serbest yolun azalması beklenebilmektedir. Dolayısıyla, reaktör basıncının 75 mtorr'dan 250 mtorr'a yükselmesi ile kaplama hızında gözlemlenen artış, gaz moleküllerinin daha çok etkileşim halinde bulunmasından dolayı olabilir [21]. Tüm plazma güçlerinde, en yüksek kaplama hızları 250 mtorr basınç değerinde elde edilmiştir. 250 mtorr'un üzerindeki basınç değerlerinde ise, reaktör basıncı arttıkça kaplama hızlarında bir düşüş gözlemlenmiştir. Bunun nedeninin, yüksek basınç değerlerinde, polimerleşme reaksiyonunu başlatacak daha yüksek enerjili gaz moleküllerinin oranın azalmasından kaynaklanmış olabileceği düşünülmektedir $[22,23]$.

Substrat sıcaklıklarının, kaplama hızlarına etkisi, sabit basınçta farklı plazma güçlerinde araştırılmıştır. Sabit basınç değeri olarak, en yüksek kaplama hızlarının elde edildiği 250 mtorr reaktör basınc1 alınmıştır. Bu kapsamda, 1, 20, 40 ve $60 \mathrm{~W}$ plazma güçlerinde, 20, 30, 40 ve $50^{\circ} \mathrm{C}$ substrat sıcaklıklarında kaplamalar yapılmıştır. Elde edilen sonuçlar Şekil 4'te gösterilmektedir. Tıpkı farklı basıç̧ta yapılan kaplamalarda gözlemlendiği gibi, en yüksek kaplama hızı tüm substrat sıcaklıklarında $20 \mathrm{~W}$ plazma gücünde elde edilirken, en düşük kaplama hızları yine $1 \mathrm{~W}$ plazma gücünde elde edilmiştir. Tüm plazma güçlerinde en yüksek kaplama hızları $20^{\circ} \mathrm{C}$ substrat sıcaklığında elde edilmiştir. Sıcaklık arttıkça, kaplama hızlarının tüm plazma güçlerinde kademeli bir şekilde azaldığı gözlemlenmiştir. Kimyasal reaksiyonlarda, sıcaklık arttıkça reaksiyon hızlarının artması beklenmektedir. Ancak, burada elde edilen sonuçlarda tam tersi bir trend gözlemlenmiştir. CVD polimerizasyon çalışmalarında kinetik temelli yüzey reaksiyonları ve adsorpsiyon temelli kaplamalar çoğunlukla aynı anda gerçekleşmektedir [24]. Substrat sıcaklıkları ve kaplama hızları arasındaki ilişkiye bakılarak, PECVD ile bu çalışmadaki mevcut koşullarda gerçekleştirilen PHPMA kaplamalarında ağırlıklı olarak adsorpsiyon modelinin baskın olduğu çıkarımı yapılabilir. 


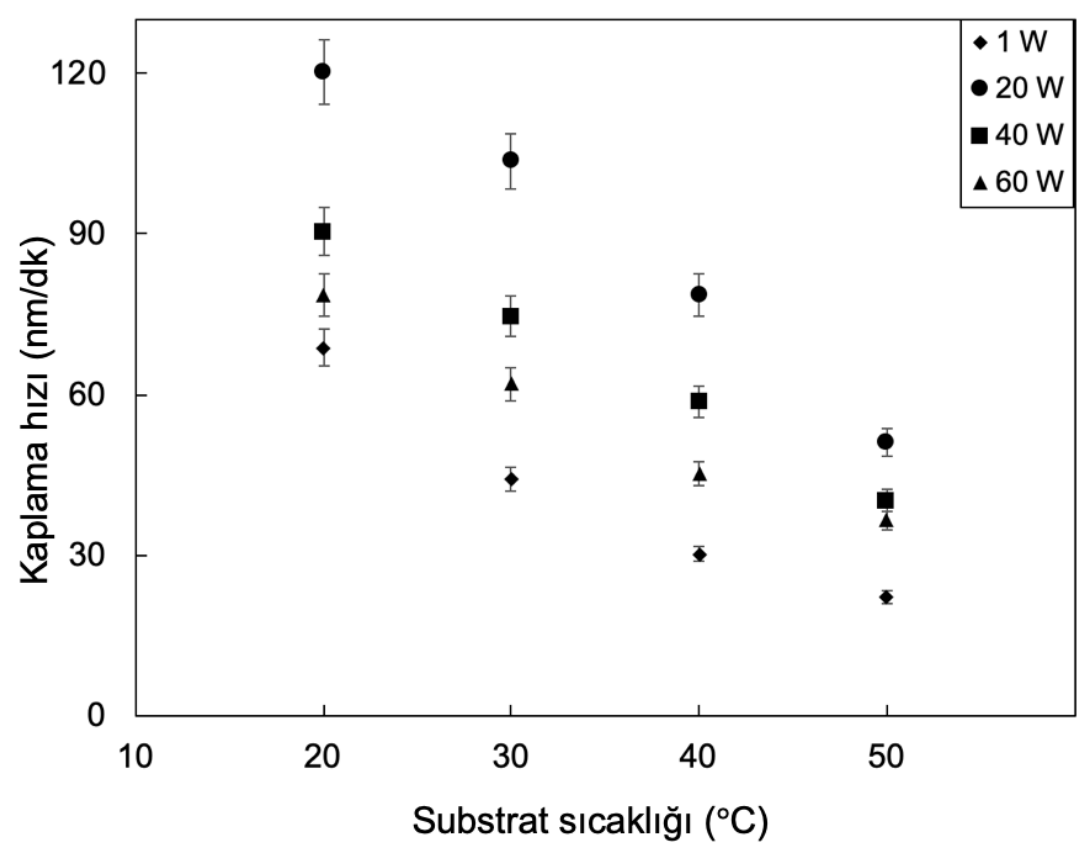

Şekil 4. Farklı reaktör basınçlarındaki plazma güçlerinin üretilen filmlerin kaplama hızlarına etkisi

PHPMA ince film kaplama kinetiği ile ilgili daha detaylı bulgulara ulaşmak için, PHPMA kaplamasının aktivasyon enerjisi hesaplanmıştır. Eğer aktivasyon enerjisi sıfirdan büyükse, polimerizasyonun kinetik modele uygun; eğer aktivasyon enerjisi negatif bir değer ise adsorpsiyon modele uygun bir kaplama gerçekleştiği söylenebilir. Bu çalışmada, aktivasyon enerjisini hesaplayabilmek için 250 mtorr reaktör basincinda, $20 \mathrm{~W}$ plazma gücündeki farkl1 substrat sıcaklıklarında elde edilen hız verileri kullanılmıştır. Söz konusu veriler kullanılarak hazırlanan yarı logaritmik formdaki grafik Şekil 5'te verilmiştir. Grafiğin eğiminden yararlanılarak, aktivasyon enerjisi $-22,16 \mathrm{~kJ} / \mathrm{mol}$ olarak bulunmuştur. Elde edilen sıfırın altındaki aktivasyon enerjisi değeri de kaplamanın adsorpsiyon mekanizması üzerinden yürüdüğünü göstermektedir.

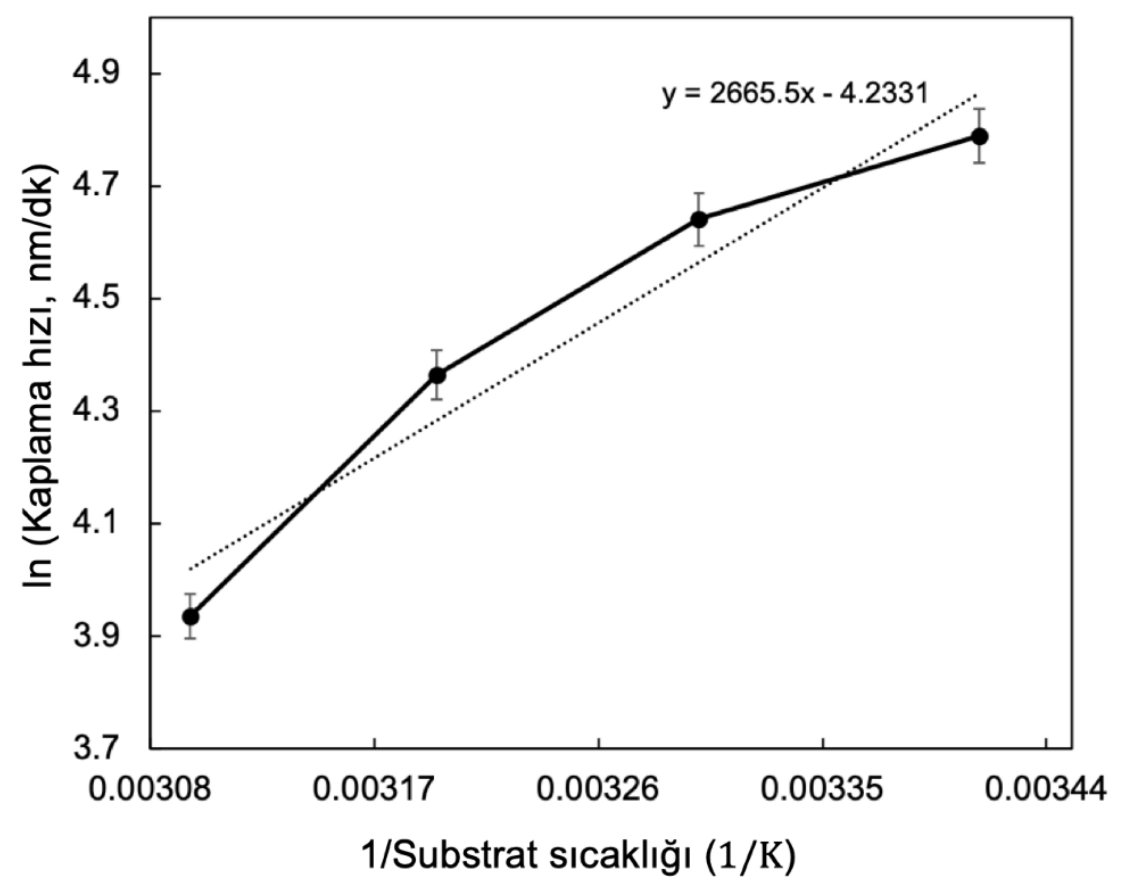

Şekil 5. 250 mtorr basınçta $20 \mathrm{~W}$ plazma gücünde, farklı substrat sıcaklıklarında elde edilen hız verileri 


\subsection{PHPMA filmlerinin kimyasal yapısı ve ıslanabilirlik özellikleri}

PHPMA ince filminin kimyasal yapısı FTIR analizi ile açığa çıkarılmıştır. Bu amaçla, en yüksek kaplama hızının elde edildiği 250 mtorr reaktör basıncında, $20 \mathrm{~W}$ plazma gücünde ve $20^{\circ} \mathrm{C}$ substrat sıcaklığında üretilen PHPMA ince filminin FTIR analizi yapılmıştır. Söz konusu FTIR spektrumu, monomerden alınan FTIR spektrumu ile karşılaştııılmalı olarak Şekil 6'da gösterilmiştir.

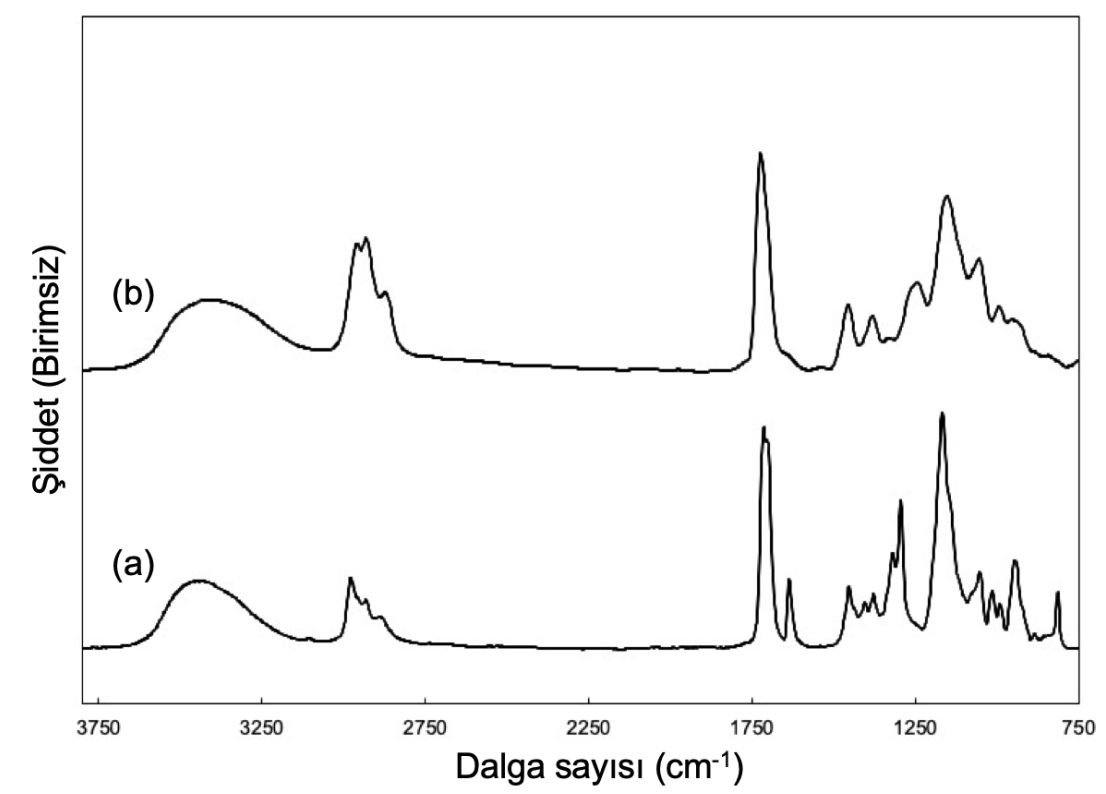

Şekil 6. FTIR spektrumları (a) HPMA monomeri, (b) PHPMA ince filmi

Şekil 6'ya bakıldığında her iki spektrumda da bulunan pikler: O-H gerilmesi $\left(3750-3050 \mathrm{~cm}^{-1}\right)$, akrilat C-H gerilmesi (3050-2800 $\left.\mathrm{cm}^{-1}\right), \mathrm{C}=\mathrm{O}$ gerilmesi $\left(1720 \mathrm{~cm}^{-1}\right), \mathrm{C}-\mathrm{C}$ gerilmesi $\left(1164 \mathrm{~cm}^{-1}\right)$ ve C-H bükülmesi $\left(1500-1350 \mathrm{~cm}^{-1}\right)[17,25]$. Öte yandan, $1633 \mathrm{~cm}^{-1}$ de yer alan $\mathrm{C}=\mathrm{C}$ gerilmesi, monomer spektrumunda gözlemlenirken, PHPMA'ya ait spektrumda gözlemlenmemiştir. Söz konusu pikin monomerde bulunurken, elde edilen polimer filmde bulunmaması, polimerleşmenin doymamış $\mathrm{C}=\mathrm{C}$ bağı üzerinden gerçekleştiğini işaret etmektedir. FTIR sonuçlarına göre monomerin yapısındaki karbonil ve hidroksil grupların iyi korunduğu görülmektedir.

250 mtorr reaktör basıncında farklı plazma güçlerinde ve farklı substrat sıcaklıklarında üretilen PHPMA ince filmleri ile kaplanmış silikon tabaka yüzeylerinden elde edilen temas açısı sonuçları Tablo 2 'de verilmiştir.

Tablo 2. Farklı substrat sıcaklıklarında ve farklı plazma güçlerinde üretilen PHPMA ince filmleri ile kaplanmış silikon tabaka üzerinden ölçülen temas açısı değerleri

\begin{tabular}{ccccc}
\hline \multicolumn{5}{c}{ Temas açısı $\left({ }^{\circ}\right)$} \\
\hline Substrat sıcaklığ & $1 \mathrm{~W}$ & $20 \mathrm{~W}$ & $40 \mathrm{~W}$ & $60 \mathrm{~W}$ \\
\hline $20^{\circ} \mathrm{C}$ & $36,2 \pm 1,0$ & $37,5 \pm 1,0$ & $40,0 \pm 1,0$ & $43,2 \pm 1,0$ \\
$30^{\circ} \mathrm{C}$ & $35,5 \pm 1,0$ & $35,9 \pm 1,0$ & $41,2 \pm 1,0$ & $41,8 \pm 1,0$ \\
$40^{\circ} \mathrm{C}$ & $36,5 \pm 1,0$ & $35,5 \pm 1,0$ & $39,7 \pm 1,0$ & $44,0 \pm 1,0$ \\
$50^{\circ} \mathrm{C}$ & $35,8 \pm 1,0$ & $37,1 \pm 1,0$ & $42,2 \pm 1,0$ & $42,3 \pm 1,0$ \\
\hline
\end{tabular}

Boş silikon tabaka yüzeyinden temas açısı, 52,5 olarak ölçülmüştür. Tablo 2'deki temas açısı sonuçlarına bakıldığında, tüm şartlarda elde edilen PHPMA ince film kaplamalarının beklenildiği üzere hidrofilik özellikte olduğu gözlemlenmiştir. Aynı plazma güçlerinde, farklı substrat sıcaklıklarında üretilen PHPMA filmlerinin yüzeylerinden ölçülen temas açısı değerleri arasında anlamlı bir fark gözlemlenmemiş̧ir. Aynı substrat sıcaklıklarında, farklı plazma güçlerinde elde edilen PHPMA ince film kaplama yüzeylerinden ölçülen temas açısı sonuçları incelendiğinde; daha yüksek plazma güçlerinde kaplanan filmlerin hidrofilik özelliklerinin, daha düşük plazma güçlerinde kaplanan filmlerden göreceli olarak daha düşük olduğu gözlemlenmiştir. Bunun nedenin, yüksek plazma 
güçlerinde reaktör ortamındaki yoğun elektron bombardımanın, filmlerin fonksiyonel gruplarını olumsuz yönde etkilemiş olmasına bağlanabilir.

Çözelti bazlı kaplama yöntemleri ile kaplanması oldukça zor olan narin yapıdaki PMMA fiber matları, PHPMA ince filmiyle kaplanmıştır. Söz konusu kaplama, en yüksek kaplama hızının elde edildiği 250 mtorr reaktör basıncında, $20^{\circ} \mathrm{C}$ substrat sıcaklığında $20 \mathrm{~W}$ plazma gücünde gerçekleştirilmiştir. Elektroeğirme PMMA fiber matlarının kaplama öncesi ve sonrası SEM görüntüleri Şekil 7'de gösterilmiştir. Kaplama sonrası fiberlerin yapısında bir kusur olmadığı net bir şekilde görülebilmektedir. Yine kaplama sonrası, fiberlerin yüzeylerinin açıkorur bir şekilde kaplandığı ve fiber matın gözenekli yapısının korunduğu gözlemlenmiştir. Kaplanmamıs PMMA fiber matlarının temas açısı, $132,7^{\circ}$ olarak ölçülürken (Şekil 7.a), PHPMA filmi ile kaplandıktan sonra $19,2^{\circ}$ olarak ölçülmüştür (Şekil 7.b).
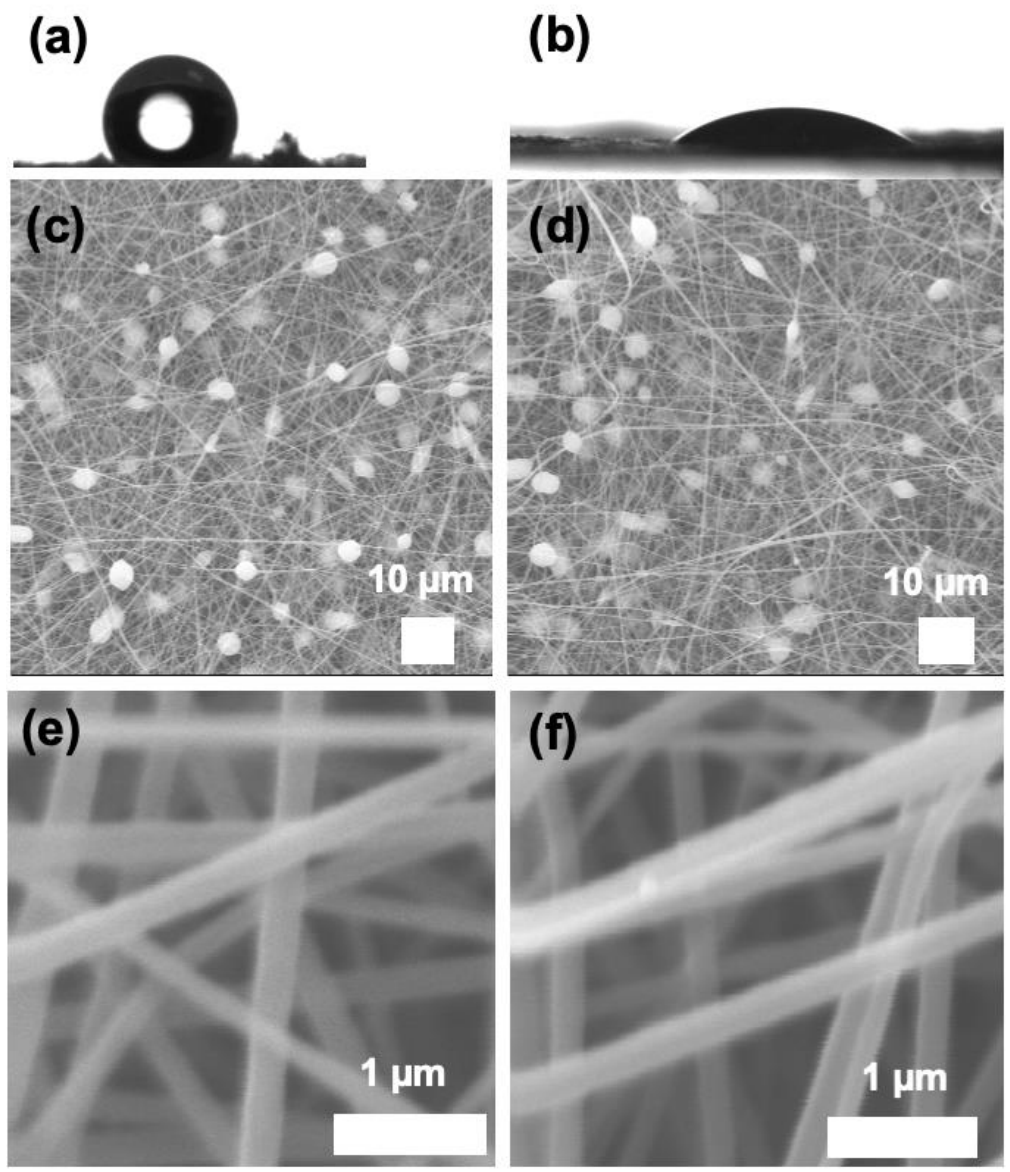

Şekil 7. (a) Kaplanmamış PMMA fiberlerin temas açısı görüntüsü, (b) PHPMA ince film kaplı PMMA fiberlerin temas açısı görüntüsü, (c) Kaplanmamış PMMA fiberlerin 1000 büyütme SEM görüntüsü, (d) PHPMA ince film

kaplı PMMA fiberlerin 1000 büyütme SEM görüntüsü, (e) Kaplanmamış PMMA fiberlerin 30000 büyütme

SEM görüntüsü, (f) PHPMA ince film kaplı PMMA fiberlerin 30000 büyütme SEM görüntüsü

Dikkat çekici bir diğer bulgu ise, PHPMA ince film kaplı PMMA fiber mat yüzeyinden, aynı koşullarda PHPMA film kaplı silikon tabakaya kıyasla daha düşük temas açısı değerinin ölçülmesi olmuştur. Yüzeylerin ıslanabilirliği üzerinde sadece yüzeyin kimyasal yapısının değil aynı zamanda yüzey morfolojisinin de etkili olduğu bilinmektedir [26]. Söz konusu temas açıları arasındaki fark, Wenzel denklemi ile açıklanabilir [27]. Denklem 1'de verilen Wenzel denklemi, yüzeylerin temas açısı ile yüzey pürüzlülüğü arasındaki ilişkiyi belirtmektedir.

$$
\cos \theta=R_{f} \cos \theta_{0}
$$

Wenzel denkleminde yer alan $\theta$ değeri, pürüzlü bir yüzeyin temas açısını; $\theta_{0}$, düz bir yüzeyin temas açısını ve $\mathrm{R}_{\mathrm{f}}$, yüzeyin pürüzlülük derecesini temsil etmektedir. Yüzey pürüzlülük derecesi, gerçek 
yüzeyin alanının; geometrik yüzey alanına bölünmesiyle bulunmaktadır. Wenzel denklemine göre, düz bir yüzeyin pürüzlülük derecesi 1 olarak kabul edilmektedir. Pürüzlü yüzeylerde, bu değer 1'den büyüktür ve pürüzlülük arttıkça da söz konusu değer büyümektedir. Bilindiği üzere, hidrofilik yüzeylerin temas açısı değeri $\left(\theta_{0}\right) 0$ ile $90^{\circ}$ arasındadır. Wenzel eşitliği göz önüne alındığında hidrofilik yüzeylerde, yüzey pürüzlülük değeri arttıkça, temas açısı değerinin azalması beklenebilir. PMMA fiberler mat yüzeyinin, silikon tabaka yüzeyinden çok daha pürüzlü olduğu aşikardır. Bundan dolayı, PMMA fiber matı gibi pürüzlü yüzey üzerine aynı şartlarda kaplanan PHPMA ince filmlerinin, silikon tabaka yüzeyine kaplanan filmlerden daha hidrofilik özellik göstermesi beklenebilir. Bu çalışmada yapılan temas açısı ölçüm sonuçlarının Wenzel denklemi ile uyum içerisinde olduğu gözlemlenmiştir.

\section{Sonuç ve Öneriler}

$\mathrm{Bu}$ çalışmada, hidrojel özellikteki PHPMA ince filmleri, çevre dostu bir yöntem olan PECVD yöntemiyle tek adımda üretilmiştir. Islak yöntemlerle kaplanması oldukça güç olan PMMA fiberlerinin yüzeylerine herhangi bir zarar vermeden başarıyla kaplanabilip; hidrofilik hale dönüştürülebilmiştir. PECVD ile kaplanan PHPMA ince filmlerinin kaplama kinetiği araştırılmıştır. Substrat sıcaklığının, reaktör basıncının ve plazma gücünün kaplama hızı üzerinde önemli bir rol oynadığı gözlemlenmiştir. Substrat sıcaklığı ve kaplama hızları arasındaki veriler incelendiğinde PHPMA kaplamalarında baskın olan mekanizmanın adsorpsiyon temelli olduğu gözlemlenmiştir. En yüksek kaplama hızı, $20^{\circ} \mathrm{C}$ 'de, 250 mtorr reaktör basıncında ve $20 \mathrm{~W}$ plazma gücünde; $120,2 \mathrm{~nm} / \mathrm{dk}$ olarak elde edilmiştir. $250 \mathrm{mtorr}$ ve $20 \mathrm{~W}$ plazma gücünde farklı substrat sıcaklıklarında yapılan kaplamalar neticesinde, kaplamanın aktivasyon enerjisi $-22,16 \mathrm{~kJ} / \mathrm{mol}$ olarak bulunmuştur.

\section{Kaynaklar}

[1] Caliari S.R., Burdick J.A. 2016. A practical guide to hydrogels for cell culture. Nature methods, 13 (5): 405-414.

[2] Ullah F., Othman M.B.H., Javed F., Ahmad Z., Akil H.M. 2015. Classification, processing and application of hydrogels: A review. Materials Science and Engineering C, 57: 414-433.

[3] Ghobril C., Grinstaff M. 2015. The chemistry and engineering of polymeric hydrogel adhesives for wound closure: a tutorial. Chemical Society Reviews, 44 (7): 1820-1835.

[4] Caló E., Khutoryanskiy V.V. 2015. Biomedical applications of hydrogels: A review of patents and commercial products. European Polymer Journal, 65: 252-267.

[5] Ahmed E.M. 2015. Hydrogel: Preparation, characterization, and applications: A review. Journal of advanced research, 6 (2): 105-121.

[6] Sevgili E., Karaman M. 2018. Başlatıcılı kimyasal buhar biriktirme yöntemi ile poli(hidroksipropil metakrilat) ince flmlerin sentezi. 13. Ulusal Kimya Mühendisliği Kongresi, 36 Eylül, Van.

[7] Delavoipière J., Heurtefeu B., Teisseire J., Chateauminois A., Tran Y., Fermigier M., Verneuil E. 2018. Swelling dynamics of surface-attached hydrogel thin films in vapor flows. Langmuir, 34 (50): 15238-15244.

[8] Green J.J., Elisseeff J.H. 2016. Mimicking biological functionality with polymers for biomedical applications. Nature, 540 (7633): 386-394.

[9] Wei M., Gao Y., Li X., Serpe M.J. 2017. Stimuli-responsive polymers and their applications. Polymer Chemistry, 8 (1): 127-143.

[10] Tokarev I., Minko S. 2009. Stimuli-responsive hydrogel thin films. Soft Matter, 5 (3): 511-524.

[11] Marí-Buyé, N., O'Shaughnessy S., Colominas C., Semino C.E., Gleason K.K., Borrós S. 2009. Functionalized, swellable hydrogel layers as a platform for cell studies. Advanced functional materials, 19 (8): 1276-1286.

[12] Schmaljohann D. 2006. Thermo-and pH-responsive polymers in drug delivery. Advanced drug delivery reviews, 58 (15): 1655-1670.

[13] Karaman M., Gürsoy M., Kus M., Özel F., Yenel E., Sahin Ö.G., Kivrak H.D. 2017. Chemical and Physical Modification of Surfaces in Surface Treatments for Biological, Chemical, and Physical Applications. Edited by Gürsoy M., Karaman M., Wiley, 23-66. 
[14] Hilding J., Grulke E.A., George Zhang Z., Lockwood F. 2003. Dispersion of Carbon Nanotubes in Liquids. Journal of Dispersion Science and Technology, 24 (1): 1-41.

[15] Chen C., Chen X., Xu L., Yang Z., Li W. 2005. Modification of multi-walled carbon nanotubes with fatty acid and their tribological properties as lubricant additive. Carbon, 43 (8): 1660-1666.

[16] Virendra K., Jerome P., Hubert R., Ilaria M., Francois R., Farzaneh A.K. 2010. Fluorocarbon Coatings Via Plasma Enhanced Chemical Vapor Deposition of $1 \mathrm{H}, 1 \mathrm{H}, 2 \mathrm{H}, 2 \mathrm{H}$-perfluorodecyl Acrylate - 2, Morphology, Wettability and Antifouling Characterization. Plasma Processes and Polymers, 7 (11): 926-938.

[17] Gürsoy M., Karaman M. 2018. Improvement of wetting properties of expanded perlite particles by an organic conformal coating. Progress in Organic Coatings, 120: 190-197.

[18] Peri S.R., Habersberger B., Akgun B., Jiang H., Enlow J., Bunning T.J., Majkrzak C.F., Foster M.D. 2010. Variations in cross-link density with deposition pressure in ultrathin plasma polymerized benzene and octafluorocyclobutane films. Polymer, 51 (19): 4390-4397.

[19] Tourrette A., De Geyter N., Jocic D., Morent R., Warmoeskerken M.M., Leys C. 2009. Incorporation of poly ( $\mathrm{N}$-isopropylacrylamide)/chitosan microgel onto plasma functionalized cotton fibre surface. Colloids and surfaces A: Physicochemical and engineering aspects, 352 (13): 126-135.

[20] Gürsoy M., Karaman M. 2016. Hydrophobic Coating of Expanded Perlite Particles by Plasma Polymerization. Chemical Engineering Journal, 284: 343-350.

[21] Pathak S.C., Hess D.W. 2008. Dissolution and swelling behaviour of plasma-polymerized polyethylene glycol-like hydrogel films for use as drug delivery reservoirs. ECS Transactions, 6 (20): 1-12.

[22] Seah M. 1981. Pure element sputtering yields using 500-1000 eV argon ions. Thin Solid Films, 81 (3): 279-287.

[23] Demircioğlu Z., Özkol E., Nasser H., Turan R. 2015. Low temperature aluminum doped zinc oxide thin film deposition on ultra-thin flexible glass and PET substrates by RF magnetron sputtering. physica status solidi (c), 12 (9-11): 1215-1219.

[24] d'Agostino R., Cramarossa F., Fracassi F., Illuzzi F. 1990. Plasma polymerization of fluorocarbons in Plasma Deposition, Treatment, and Etching of Polymers. Edited by d'Agostino R. Academic Press Inc. 95-162.

[25] Gürsoy M., Ucar T., Tosun Z., Karaman M. 2016. Initiation of 2-Hydroxyethyl Methacrylate Polymerization by Tert-Butyl Peroxide in a Planar PECVD System. Plasma Processes and Polymers, 13 (4): 438-446.

[26] Cassie A., Baxter S. 1944. Wettability of porous surfaces. Transactions of the Faraday society, 40: 546-551.

[27] Wenzel R.N. 1949. Surface Roughness and Contact Angle. The Journal of Physical and Colloid Chemistry, 53 (9):1466-1467. 